\title{
Serrated Flow in Quenched Duralumin Alloy
}

\author{
By SRINIVASAN
}

Materials Science Division

National Aeronautical Laboratory

Bangalore 17, India

Received 4 October 1972

\section{ABSTRACT}

A nodel based on solute-dislocation interaction is proposed for dynamic strain ageing in substitutional alloys. Postulating on the basis of available experimental evidence that moving dislocations and their average velocity are dependent on the applied strain rate $\dot{\epsilon}$ and test temperature $T$, a relation

$$
t_{\mathrm{c} \mathrm{K}}=(\text { constant }) \frac{1}{\epsilon^{\prime / 2}} \exp \left(\frac{Q_{\mathrm{H}}-H}{2 k T}\right),
$$

is derived where $t_{\mathrm{CI}}$ is the time interval between the onset of plastic deformation and the appearance of first serration. This theory is applied to experimental observations of serrated flow in quenched duralumin alloy (D.T.D. 610 B): the effective activation energy $\left(Q_{\mathrm{M}}-H\right)$ for the dynamic strain ageing process, solute migration energy $Q_{\mathrm{y}^{\prime}}$ and an activation energy $H$ associated with an intrinsic process of dislocation multiplication-motion are evaluated to be $0 \cdot 23,0.33$ and $0.1 \mathrm{eV}$, respectively, for the alloy. It is suggested that copper-magnesium pair with a migration energy as the above value $0-33 \mathrm{eV}$ causes necessary dislocation locking for the occurrence of serrated flow. In addition, the present analysis shows that during the dynamic strain ageing, moving dislocation density should decrease with increasing strain rate and decreasing test temperature.

\section{$\S 1$. INTRODUCTION}

DURALUMIN is an age hardenable aluminium-base alloy containing copper and magnesium as major alloying additions. Serrations are observed in the stress-strain curves of this alloy when it is in the quenched condition. It is surprising that though this was one of the earliest alloys to be investigated by Portevin and Le Chatelier (1923), the dynamic strain ageing in this alloy has not, as yet, been quantitatively studied. In this paper we report the results obtained on the dynamic strain ageing behaviour of this alloy.

Section 2 of this paper deals with a generalized treatment of dynamic strain ageing based on solute-dislocation interaction. An equation is derived relating the experimentally measured macroscopic parameters such as the applied strain rate and the test temperature to the delay time. In 
$\$ \$ 3$ to 5 this theory is applied to experimental observations during dynamic strain ageing in quenched commereial D.T.D.610B duralumin alloy. Certain inferesting implications of this theory are also discussed in this paper.

\section{§ 2. A Model for Serrated Yieldivg}

That solute-dislocation interaction causes load drops in stress-strain curves is well known (Cottrell 1958, Cottrell and Jaswon 1949). A generalized model on the basis of this interaction for dynamic strain ageing is proposed in this section.

During a tensile test, solutes will immobilize moving dislocations by forming atmospheres around them. This locking occurs only when the mobility of solutes is sufficiently high, and leads to a situation wherein the internal plastic strain rate falls below that of the externally applied strain rate. Such a situation is unstable and results in a sudden generation of new mobile dislocations; or release of locked dislocations, to raise the internal plastic strain rate back to the applied level. Such spurts of new mobile dislocations are manifest as load drops. A continual repetition of this phenomenon of periodic locking and unlocking of dislocations results in serrated stress-strain curves.

As is common with all ageing phenomena, this dynamic strain ageing is also time-dependent. There exists a finite time $t_{\mathrm{cr}}$ between yicld and the first observation of a load drop. This we shall refer to as 'delay time' $t_{\mathrm{cr}}$. Other investigators have generally been concerned only with the strain at the onset of serrations, generally known as critical strain $\epsilon_{\mathrm{er}}$. It is easily seen that this delay time $t_{\mathrm{or}}$ is a function of applied strain rate $\dot{\epsilon}$ and test temperature $T^{\circ} \mathrm{K}$, as any change induced in these two variables affects the solute mobility and dislocation velocity.

To derive a functional relation between the delay time $t_{\mathrm{cr}}$, the applied strain rate $\dot{\epsilon}$ and the test temperature $T$, let us consider an edge dislocation of unit length moving with a uniform velocity $v$ on its slip plane. The interaction between this dislocation and solutes will be of importance only for those solutes which are within a critical distance $Y_{\mathrm{cr}}$ on either side of the slip plane. Solutes that come within this eritical interaction distance, will form atmospheres around the moving dislocation, thereby immobilizing it. The eritical distance $Y_{\text {cr }}$ has been shown by Yoshinaga and Morozumi (1971) to be

$$
\left|Y_{\mathrm{cr}}\right|=1 \cdot 707\left(\frac{A D}{k T v}\right)^{1 / 2},
$$

where

$$
A=\frac{41+v}{3} \frac{1-v}{1-v e r}{ }_{\mathrm{M}^{3}}
$$

and

$$
D=D_{0} \exp \left(-\frac{Q_{\mathrm{M}}^{\prime}}{k T}\right)
$$

Symbols in the above equation have the following significance:

$$
\begin{aligned}
A & =\text { strength of interaction, } \\
D & =\text { diffusion coefficient of solutes, } \\
k & =\text { the Boltzmann constant, } \\
T & =\text { absolute temperature, } \\
v & =\text { the Poisson rat io of the matrix, } \\
\mu & =\text { shear modulus of the matrix, } \\
b & =\text { the Burgers vector, } \\
e & =\text { lattice strain due to the presence of solute, } \\
r_{3} & =\text { radius of the matrix atom, } \\
D_{0} & =\text { a constant, and } \\
Q_{\mathrm{N}}{ }^{\prime} & =\text { the activation energy for solute migration. }
\end{aligned}
$$

The number of solute atons with which the moving dislocation interacts in a unit time is, therefore,

$$
n=2\left|Y_{\mathrm{cr}}\right| v c_{0},
$$

where $c_{0}$ is volume concentration of solute.

The delay time $t_{c r}$ will be inversely dependent on $n$, and will decrease with increasing $n$ since a large $n$ implies rapid locking, i.e.

$$
t_{c r}=\alpha / n \quad(\alpha \text { is a constant }) .
$$

From eqns. ( $1 a),(2)$ and (3), it follows that

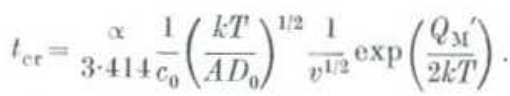

In deriving the above eqn. (4), we have tacitly assumed that an edge dislocation of unit length moves with a discrete velocity $v$. But in reality, we can only talk of an aggregate of moving dislocations, commonly referred to as mobile dislocation density $\rho_{\mathrm{m}}$ with an average velocity $\tilde{v}$. Both $\rho_{\mathrm{m}}$ and $\bar{v}$ are likely to be dependent on strain rate and temperature, and it is difficult to evaluate this dependence for the two variables independently, unless certain simplifying assumptions are made. A reasonable estimate of this dependence for moving dislocation density can be obtained if we assume that this density is linearly dependent on total dislocation density, $\rho_{t}$. Strain-rate and temperature dependence of the total dislocation density during dynamic strain ageing can be determined from available experimental data. These experimental data (Edington and Smallman 1964, Wilcox and Smith 1964) suggest a relation of the following type for the variation of $\rho_{\mathrm{t}}$ with strain rate and temperature:

$$
\rho_{\mathrm{t}}=\rho_{0}\left(\frac{\hat{\epsilon}}{b}\right)^{p} \exp \left(-\frac{H}{k T}\right) .
$$


Here $\rho_{0}$ and $p$ are constants and $H$ is an activation energy associated with an intrinsic process of dislocation multiplication-motion. Hence, for the variation of moving dislocation density $\rho_{1 \text { w }}$ we get

$$
\rho_{m}=R \rho_{\mathrm{t}}=R \rho_{0}\left(\frac{\dot{\epsilon}}{b}\right)^{p} \exp \left(-\frac{H}{k T}\right),
$$

where $R$ is a constant.

From the Orowan equation

$$
\dot{\epsilon}=\beta \rho_{\mathrm{m}} b \bar{x} \quad(\beta \text { is constant }) .
$$

it is possible to obtain a relation for the dependence of average velocity $\tilde{v}$ on strain rate and temperature:

$$
\bar{v}=v_{0}\left(\frac{\dot{\epsilon}}{\vec{b}}\right)^{q} \exp \left(\frac{H}{k T}\right),
$$

where $q=1-p$ and $v_{0}$ is a constant and equal to $1 / R \rho_{0} \beta$.

The delay time $t_{\mathrm{cr}}$ can now be evaluated using eqns. (4) and (7) to be

$$
t_{\text {cr }}=\frac{\alpha}{3+414}\left(\frac{k T R \rho_{0} \beta b^{q}}{c_{0}^{2} A D_{0}}\right)^{1 / 2} \frac{1}{\epsilon^{q / 2}} \exp \left(\frac{Q_{\mathrm{M}}^{\prime}-H}{2 k T}\right), \ldots .
$$

or,

$$
\log t_{\mathrm{er}}=\log \left[\frac{\alpha}{3 \cdot 414}\left\{\frac{k T R \rho_{0} \beta b^{q}}{c_{0}{ }^{2} A D_{0}}\right\}^{1 / 2}\right]-\frac{q}{2} \log \dot{\epsilon}+\frac{\left(Q_{\mathrm{M}}{ }^{\prime}-H\right)}{4 \cdot 6 k T} .
$$

The validity of the above equation can be tested experimentally.

\section{§3. ExPERIMENTAL}

The starting material in this investigation was duralumin D.T.D.610 B alloy whose nominal chemical composition is given in table 1 . Tensile specimens of $12.5 \mathrm{~mm}$ gauge length were milled from a rolled sheet of $0.7 \mathrm{~mm}$ thickness with grains parallel to the tensile axis. Before testing, these specimens were solution-treated at $507^{\circ} \pm \mathrm{I}^{\circ} \mathrm{C}$ for about $30 \mathrm{~min}$ and water quenched.

Tensile tests were carried out in an Instron testing machine. Three strain rates corresponding to the cross head speeds of $0.05 \mathrm{~mm} / \mathrm{min}$, $0.5 \mathrm{~mm} / \mathrm{min}$ and $1.0 \mathrm{~mm} / \mathrm{min}$ were employed, and tests were carried out at temperatures ranging from $230^{\circ}$ to $295^{\circ} \mathrm{K}$. A clear delineation of serrations and the absence of age-hardening at test temperatures determined the choice of the above temperatures and strain rates.

Table 1. Nominal chemical composition of D.T.D. 610 B duralumin alloy in weight per cent

\begin{tabular}{|c|c|c|c|c|c|c|}
\hline Element & $\mathrm{Cu}$ & $\mathrm{Mg}$ & $\mathrm{Si}$ & $\mathrm{Fe}$ & $\mathrm{Mn}$ & $\mathrm{Al}$ \\
\hline wt. $\%$ & $3 \cdot 8-4 \cdot 8$ & $0 \cdot 55-0 \cdot 85$ & $0 \cdot 6-0 \cdot 9$ & $0 \cdot 5$ & $0 \cdot 4-1 \cdot 2$ & Rest \\
\hline
\end{tabular}

\section{\$4. RESULTS}

\subsection{General Observations}

The load-extension curves of this alloy were smooth to start with, and then serrations began to appear in them at all three strain rates over the entire range of test temperatures. Plastic strain at which serrated flow started was dependent on strain rate and test temperature, and varied from $2 \cdot 5$ to $6 \cdot 1 \%$ in this alloy. Each load drop was accompanied by a narrow band of localized plastic deformation crossing the width of the specimen at an angle of about $50^{\circ}$ to the tensile axis. Audible 'clicks' were heard during such load drops. The magnitude of load drops increased with increasing plastic strain.

All the three types of serrations as defined by Brindley and Worthin gton (1970) were observed. Type A and Type B were found to occur at temperatures between $230^{\circ}$ and $260^{\circ} \mathrm{K}$ while type $\mathrm{C}$, characterized by load drops below the extrapolation of the smooth stress-strain curve was observed at temperatures between $260^{\circ}$ and $295^{\circ} \mathrm{K}$. These types of serrations were also found to be strain-rate sensitive. A possible explanation for these three types has been advanced elsewhere (Srinivasan, to be published).

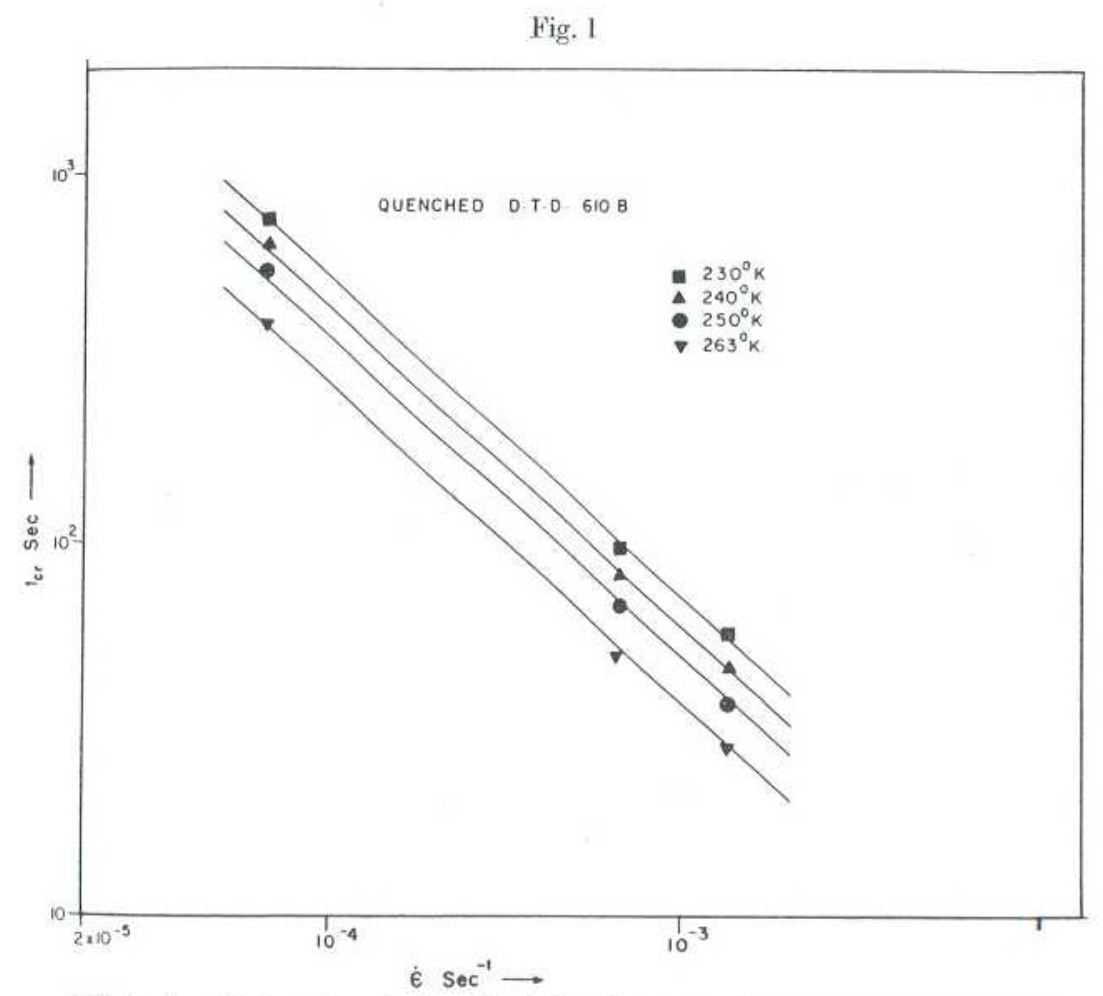

Effect of applied strain rate $\dot{\epsilon}$ on the delay time $t_{\mathrm{cr}}$ various at test temperatures. 
4.2. Trriation of Delay Time with Strain Rate and T'est Temperature

The plastic extension at the onset of serrations was read from the recorded stress-strain eurve, and the corresponding delay time $t_{\text {cr }}$ was computed from the knowledge of the cross head speed.

The effect of strain rate and temperature on the delay time $l_{e \cdot \mathrm{r}}$ is shown in fig. 1. Log $t_{c r}$ decreases linearly within creasing $\log \dot{\epsilon}$ at constant temperature. Increasing the test temperature merely shifts this curve towards abscissa keeping the slope constant. This slope was evaluated to be -0.87. From this slope $q$ was calculated to be 1.74.

Figure 2 shows the dependence of $\log t_{\mathrm{er}}$ on test temperature when the applied strain rate is kept constant. On increasing the test temperature $\log t_{\mathrm{er}}$ decreased, and a straight line plot between $\log t_{\mathrm{cr}}$ and $I / T$ with a slope equal to $0.58 \times 10^{3} \mathrm{~K}$ was obtained.

Fig. 2

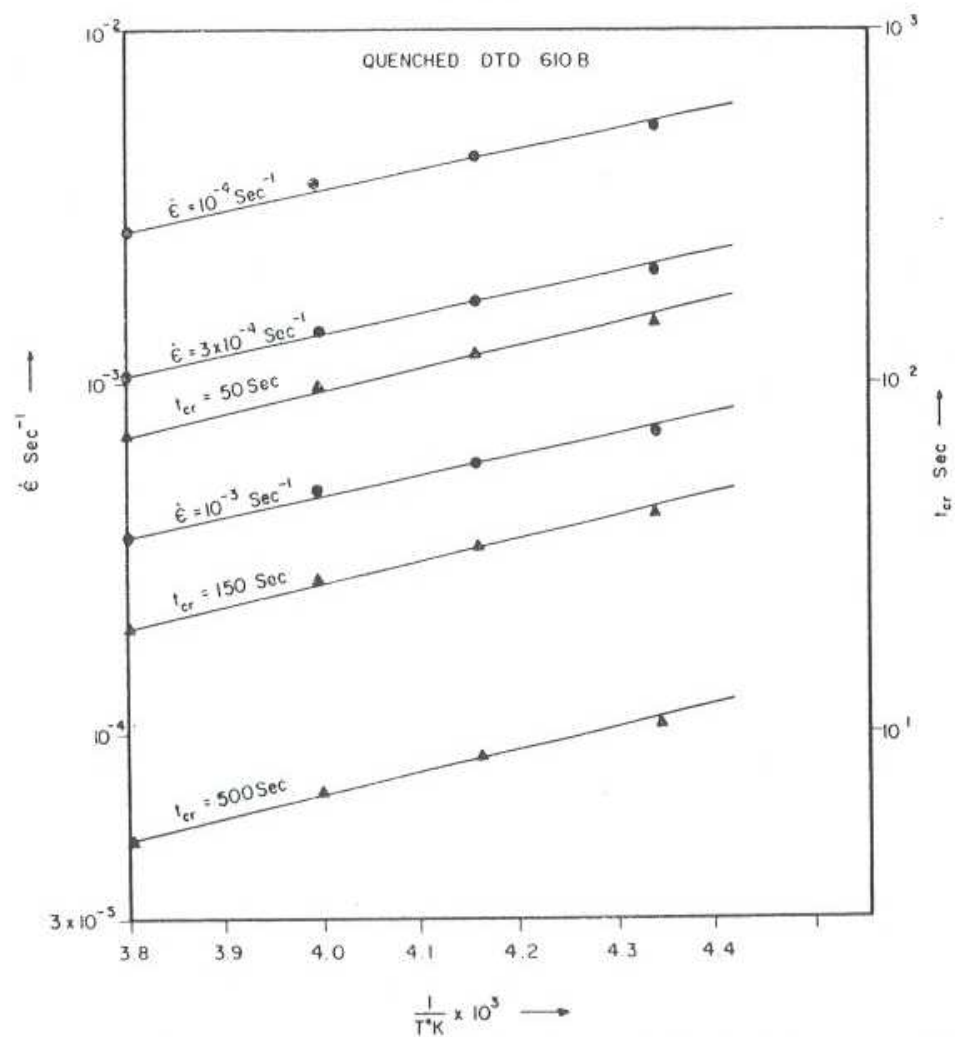

The relationship between the delay time $t_{\mathrm{cr}}$ and reciprocal of test temperature $1 / T$ at various strain rates ( - - ) and the relationship between the strain rate $\dot{\epsilon}$ and reciprocal of test temperature $1 / T$ at various delay times $t_{\mathrm{cr}}(-\mathbf{A}-)$.
The variation of log $\dot{\epsilon}$ with temperature at constant critical time is shown in the same fig. ${ }^{2}$, and this is essentially a cross -plot of fig. I at different $t$... Log $\dot{\epsilon}$ increases linearly with increasing $\int / T$ and the slope $\left(\partial \log \epsilon / \partial \mathbf{l} / T^{\prime}\right)_{\mathrm{er}}$ has a value of $0 \cdot\left(i t \times 10^{3} \mathrm{~K}\right.$

The above observations of the effect of strain rate and test temperature on the delay time are as predieted by the eqn. (s b) derived earlier in $\$ 2$.

An effective activation energy $\left(Q_{V I}{ }^{\prime}-H\right)$ for dynamic strain ageing process could be evaluated from the above slopes using the relation

$$
+\cdot 6 k\left(\frac{\partial \log t_{\mathrm{cr}}}{\partial(1 / T)}\right)_{\epsilon}=2 \cdot 3 k_{q}\left(\frac{\partial \log \dot{\epsilon}}{\partial(1 / T)}\right)_{t_{\mathrm{cr}}}=\left(Q_{\mathrm{Mr}}{ }^{\prime}-H\right),
$$

and is found to be $0 \cdot 23 \mathrm{eV}$ for this alloy.

\section{3. 'Strength Peaks' in the Flow stress-temperature Plot}

Variation of $0 \cdot 2 \%$ flow stress with temperature at two different strain rates is shown in fig. 3. The flow stress decreases monotonically with temperature and then exhibits a peak at both strain rates. The higher the applied strain rate, the higher is the temperature at which the strength peak is observed.

Fig. 3

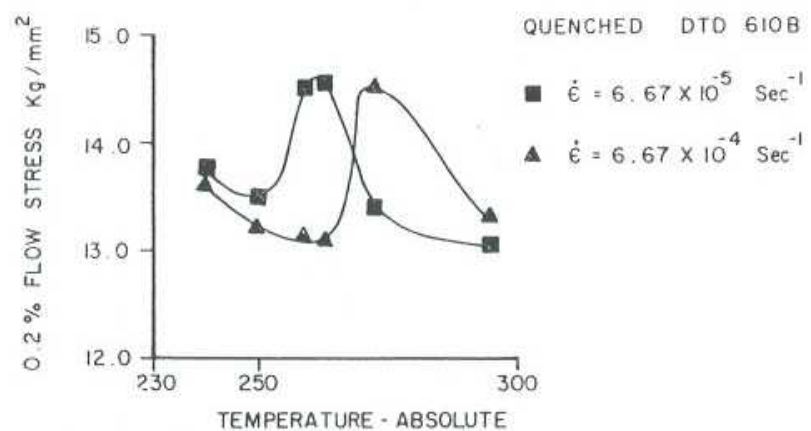

Variation of $0 \cdot 2 \%$ flow stress with absolute temperature at two strain rates. Strength peaks at both the strain rates can be clearly seen.

\section{§.5. Discussion}

The above observations show that the dynamic strain ageing in this quenched duralumin alloy is associated with

(a) an effective activation energy $0 \cdot 23 \mathrm{eV}$ equal to $Q_{\mathrm{y}}{ }^{\prime}-H$ for this process ;

(b) an inverse strain rate dependence of moving dislocation density, and

(c) strength peaks in the plot of flow stress versus temperature. 
It remains to identify the solute atom responsible for dynamic strain ageing in this alloy, and also to examine the implications and generality of the observations of an inverse strain rate effect on moving dislocation density, and the strength peaks in flow-stress temperature plot.

\subsection{On the Activation Energy for Solute Migration}

An effective activation energy $0 \cdot 23 \mathrm{eV}$ evaluated from the slopes $\left.\mid \partial \log t_{\mathrm{cr}} / \partial \mathrm{I} / T\right]_{\epsilon}$ and $[\partial \log \dot{\epsilon} / \partial \mathrm{I} / T]_{t_{\mathrm{er}}}$ does not correspond to activation energy for solute migration alone. In addition, this includes a contribution from an intrinsic process of dislocation multiplication-motion. There is no direct experimental evidence at present to suggest a value of $H$ for this process. However, an approximate value for $H$ can be derived by considering $\left(Q_{\mathrm{M}}{ }^{\prime}-H\right)$ values obtained for different aluminium alloys using the above model as $H$ is essentially a property of the matrix dislocation.

Table 2. Values of effective activation energy $\left(Q_{M}{ }^{\prime}-H\right)$ for dynamic strainageing process in various aluminium-base alloys

\begin{tabular}{|c|c|c|}
\hline Alloy & $\left(Q_{\mathrm{M}}{ }^{\prime}-H\right) \mathrm{eV}$ & \multicolumn{1}{|c|}{ Reference } \\
\hline $\mathrm{Al}-2 \cdot 36$ at. $\% \mathrm{Zn}-2 \cdot 87$ at. $\% \mathrm{Mg}$ & $0 \cdot 40$ & $\begin{array}{l}\text { Mukherjee, D'Antonio, } \\
\text { Maciag and Fisher } \\
(1968)\end{array}$ \\
\hline $\mathrm{Al}-1.94$ at. $\% \mathrm{Cu}-1.72$ at. $\% \mathrm{Mg}$ & $0 \cdot 40$ & $\begin{array}{l}\text { Mukherjee, May, } \\
\text { Maciag and D'Antonio } \\
(1970)\end{array}$ \\
\hline $\mathrm{Al}-0.7$ at. $\% \mathrm{Mg}$ & $0 \cdot 46$ & $\begin{array}{l}\text { MacEwen and } \\
\text { Ramaswami }(1970)\end{array}$ \\
\hline
\end{tabular}

Values of $\left(Q_{\mathrm{M}}{ }^{\prime}-H\right)$ for various Al-base alloys are shown in table 2. These values remain fairly constant for all aluminium-base alloys suggesting that the common solute, magnesium, is likely to cause the necessary dislocation pinning for serrated flow in them. As migration energy for vacancy in aluminium and binding energy of magnesium with vacancy are known to be $0.75 \mathrm{eV}$ (Bass 1967) and $0 \cdot 2 \mathrm{eV}$ (Perry and Entwistle 1968), respectively, the value of $H$ could be estimated to be $0 \cdot 1 \mathrm{eV}$ approximately.

Using the above value of $H, Q_{\mathrm{M}}{ }^{\prime}$, solute migration energy in this quenched alloy is evaluated to be $0 \cdot 33 \mathrm{eV}$. This value agrees with the activation energy for migration of copper-magnesium pair obtained in studies on ageing kinetics of a similar 2024 duralumin alloy (Gefen, Rosen and Rosen 1971). It is therefore suggested that copper-magnesium pair acts as solute responsible for necessary dislocation pinning in this alloy.
5.2. On the Variation of Motile Dislocation Density with Strain Rate uret Temperature.

The eqn. $5(a)$ describes strain rats-and temperature-dependence of moving dislocation density, and has its basis in the experimental observations in vanadium (Edington and Smallman 1964) and $\mathrm{Ni}-\mathrm{H}$ (Wilcox and Smith 1964). The exponent in this equation is evaluated to be $-0 \cdot 7+$ for this quenched alloy: This value of $p$ is characteristic of moving dislocation density as the experimental data used for its evaluation were essentially obtained during tensile tests, and implies that moving dislocation density decreases with increasing strain rate. It is very difficult at present to test this dependence by a direct measurement of moving dislocation density at various strain rates. Even experimental evidence as to the variation of total dislocation density with strain rate in duralumin alloy is not available to test the above inference.

Moving dislocation density at a constant strain rate increases with temperature, and is characterised by an activation energy $0.1 \mathrm{eV}(\$ 5.1)$, associated with an intrinsic process of dislocation multiplication-motion. It is believed that this intrinsic process is very similar to the one proposed to explain Bordoni peaks in aluminium (Niblett 1966).

The above observations show that the empirical relations

and

$$
\left(\frac{\partial \log \rho_{\mathrm{mit}}}{\partial \log \dot{\epsilon}}\right)_{\epsilon, T}=\left(\frac{\partial \log \rho_{\mathrm{t}}}{\partial \log \dot{\epsilon}}\right)_{\epsilon, T}=-0 \cdot 74<0,
$$

$$
\left(\frac{\partial \log \rho_{\mathrm{m}}}{\partial \log T}\right)_{\mathrm{c}, \dot{\varepsilon}}=\left(\frac{\partial \log \rho_{\mathrm{t}}}{\partial \log T}\right)_{\varepsilon, \dot{\varepsilon}}=\frac{0 \cdot 1 \mathrm{eV}}{2 \cdot 3 k T}>0
$$

suggested by Wilcox and Rosenfield (1966) are valid for this alloy also.

\subsection{On the Strength Peak, and its Relation to the Serrated Flow}

In the temperature range from $250^{\circ}$ to $295^{\circ} \mathrm{K}$ strength peaks, as shown in fig. 3 , have been observed in $0 \cdot 2 \%$ flow stress-temperature plot. These strength peaks are manifestations of strengthening process associated with dynamic strain ageing. Moving dislocations experience a drag stress from the lingering solute atmospheres and need, therefore, an additional stress for their motion. This stress at different test temperatures appears as a hump in an otherwise monotonically decreasing curve of flow stress versus temperature.

From the experimental observations on the dynamic strain ageing behaviour of various alloys it has been suggested that the relations $(\partial \log \sigma / \partial \log \dot{\epsilon})_{\epsilon, T}<0$ (i.e. negative strain-rate sensitivity) and

$$
(\partial \log \sigma / \partial \log T)_{\epsilon, \epsilon}>0
$$

will be valid when serrated flow occurs (Wilcox and Rosenfield 1966). However, in the present investigation it is observed that not only the above relations but relations of the type 
and

$$
(\partial \log \sigma \partial \log \dot{\epsilon})_{\epsilon} T>0
$$

$$
(\partial \log \sigma / \partial \log T)_{\varepsilon, \varepsilon}<0
$$

are also associated with serrated flow; for serrated flow in this quenched alloy has been observed over the range of temperatures in which the strength peaks appear.

\section{\$6. SUMMARY}

Dynamic strain ageing oceurs in quenched duralumin alloy between $230^{\circ}$ and $295^{\circ} \mathrm{K}$, and is associated with a serrated stress-strain curve and a strengthening process. There is always a finite time interval $t_{\text {er }}$ between the yield and the appearance of first serration and this delay time $t_{\mathrm{cr}}$ is dependent on the applied strain rate and test temperature. These observations are rationalized by a model based on solute-dislocation interaction, and this analysis indicates that the moving dislocation density in this alloy decreases at constant strain and temperature with the applied strain rate during dynamic strain ageing. Activation energy evaluated from the above observations suggests that copper-magnesium pair is likely to be responsible for dymamic strain ageing of this alloy:

\section{ACKNOWLEDGMENTS}

The author is grateful to Dr. V. S. Arunachalam and Professor B. Ramaswami for useful discussions and to 1r. S. Rameseshan Head, Materials Science Division, and to Dr. S. R. Valluri, Director, National Aeronautical Laboratory for encouragement.

\section{ReFerences}

Bass, J., 1967, Phil. Mag., 15, 717.

Brindley, B. J., and Worthingtos, P. J., 1970, Metall. Rev., 145, 101.

Cotтrels. A. H., 1958, Vacancies and Other Point Defects in Metals and Alloys (London: Inst. Metals), p. 1.

Cottrell, A. H., and JAswon, M. A., 1949, Proc. R. Soc. A, 199, 104.

Edington, J. W., and Strallaman, R. E., 1964, Acta metall., 12, 1313.

Gefen, Y., Rosen, M., and Rosen, A. 1971, Mater. Sci. Engng, 8, 181.

MacEwen, S. R., and Ramaswami, B., 1970, Phil. Mag., 22, 1025.

Mukherjee, K., D'Antonio, C., MactaG, R., and Fisher, G., 1968, J. appl. Phys, 39, 5434.

Mukherjee, K., May, T., Mactag, R. J., and D'Antonio, C., 1970, Mater. Sci. Engng, 6, 334.

Nibletr, D. H., 1966, Physical Acoustics (Principles and Methods) III, Part A: The Effect of Imperfections, edited by Warren P. Mason (New York and London: Academic Press), p. 115.

Perry, A. J., and Entwistue, K. M., 1968, J. Inst. Metals, 96, 344.

Portevis, A., and Le Chatelier, F., 1923, C.r. hebd.Séanc. Acad. Sci., Paris, 176,507 .

Wilcox, B. A., and Rosenfield, A. R., 1966, Mater.Sci.Engng., 1, 201.

Wrucox, B. A., and Sмттн, G. C., 1964, Acta metall., 12, 371.

Yoshinaga, H., and Morozumi, S., 1971, Phil. Mag., 23, 1371. 